\title{
Peculiarities on Sustainability at Higher Education Sector: A Case Study
}

\author{
Serene Dalati \\ Management Department, Faculty of Business Administration, Arab International \\ University, Syrian Arab Republic \\ s-dalati@aiu.edu.sy
}

\begin{abstract}
This research paper provides an overview of sustainability in higher education, emphasizing its significance in the scope of environmental, social, and economic initiatives. A clarification between an old and new paradigm is examined, highlighting the challenges, which face the higher education sector. The research provides a case example on sustainability in higher education in the South Mediterranean region, drawing on the case of Syrian higher education.
\end{abstract}

Keywords: Economic sustainability, social sustainability, environmental sustainability, higher education sector, Syria. 


\section{Introduction}

The new global reality requires agile and sustainable rules and approaches in the scope of academic learning and research environment. The focus will be on creating a balance between short-term benefits and long-term financial, social, and environmental sustainability. Therefore, universities operating in the new reality need a sustainable management paradigm.

Sustainability is defined in diverse approaches. According to previous studies on sustainable higher education, higher education institutions need to develop green and smart approaches in managing their structure (Barth et al., 2007; Haavisto and Kovács, 2014, Nomura and Abe, 2010). Sustainable development is the development that meets the needs of the present without compromising the ability of future generations to meet their own needs. The term development examines social, economic, and environmental dimensions concerning sustainability. Social sustainability focuses on providing equal prospects, including physiological needs, such as housing, security, education, healthcare, and employment. Environmental sustainability observes and scrutinizes topics associated with the environmental protection of natural resources.

A recent project on sustainability presumes that resources are limited and should be used conservatively and wisely with a view to long-term priorities and consequences of the ways in which resources are used. In simplest terms, sustainability is about our children and our grandchildren, and the world we will leave them (ULSA, 2021).

\section{Challenges facing Higher Education Institutions for Sustainability}

Higher education institutions have a significant responsibility to respond to current global challenges on different levels. Perhaps one of the biggest challenges of the higher education institutions is to address ways to operationalize sustainability and develop actions of implementing the plan sustainable higher education.

Universities' infrastructure comprises university campus and university services, including lecture classes, restaurants, sports facilities, students' residences, library resources, computer laboratories, and other facilities. In this scope, higher education institutions have to implement sustainability initiatives in their management operating systems and infrastructures. Moreover, universities are requested to promote and integrate the concept of sustainability in their curricula (Pedro et al., 2015).

Challenges for sustainable higher education includes establishing sustainability education and curriculum, working on research and green campus operations, developing staff and rewards system (Beringer 2008).

According to Jose and Chacko (2016), the higher education sector is critical to economic development at the national level, and creating sustainability measures is 
challenging for universities at the national level.

\section{The Context for Sustainability in Higher Education in the Middle East}

Based on previous research, sustainability is examined in three initiatives: social, economic, and environmental (Jose and Chacko 2016). Whereas environmental sustainability initiative explores factors related to accountability to protect the natural environment, focusing on waste and pollution reduction, energy efficiency, reducing the consumption of toxic materials, recycling, and eventually a "Green Campus" (Wright, 2002).

Consequently, the social aspect of sustainability clarifies initiatives related to human capacity building and improving internal and external communities, building networks with society, fighting poverty. Also, social sustainability focuses on university staff and employees, encouraging diversity, equality, equity, and developing democratic governance and horizontal organizational structures. Economic and financial sustainability initiative focuses on securing revenue schemes and cash flow stability and maintaining above-average returns to higher education institutions stakeholders.

According to Dalati (2021), the assumption is that the prevalent organizational environment of higher education institutions in the South Mediterranean region is generally considered as a traditional paradigm, which is characterized by the following:

1. There is a deficiency of sustainable development training programs for its human academic resources scope faculty and sustainable institutional leadership, and a lack of mentoring schemes at higher education institutions.

2. Lack of integration of sustainability at courses and curricula levels.

3. Lack of strategic planning which would incorporate sustainability in higher education in institutions visions and mission statements;

4. Organizational structures emphasize vertical hierarchy and bureaucratic systems.

5. Lack of management and leadership development training programs makes it hard for men and women to develop their careers and managerial experience as schools and institutional leaders.

The reality in most Arabic regions is that early-career academics struggle within old and traditional hierarchies, which emphasize centralization, vertical hierarchy, command, and control, divide, and concur management approaches. The new sustainability paradigm in higher education is characterized by transformation from managing with stability and keeping running institutions steadily to change and sustainable and crisis management. Adaptation with a new twenty-first-century reality is a characteristic dimension of effective management in the new paradigm.

The new sustainability paradigm in higher education is characterized by 
transformation from bureaucratic management to empowerment and facilitation. Today the old assumption about the unequal distribution of power is replaced by a new vision for transforming higher education institutions in the South Mediterranean region to be empowered, where the intellectual capacity of all employees is crucial.

The new sustainability paradigm in higher education is characterized by transformation from traditional competition to collaboration. The old assumption of competition and a closed system is replaced by a new vision for transforming cooperation and competition.

The new sustainability vision in higher education emphasizes transformation from traditional uniformity, separation, and specialization to diversity, integration, and cross-functionalization. The new sustainability paradigm in higher education highlights the change from traditional management, characterized by functional management, which emphasizes vertical hierarchy to introducing horizontal, and team management.

\section{Sustainable Higher Education in Syria}

Examining the higher education sector in Syria Before 2011, it expanded as the introduction of private universities in Syria through legislation, which was applied in 2001, allowed the operation of Syrian private higher education institutions. This was accompanied by the adoption of more free-market economic policies. Establishing private banks and insurance companies was also allowed, flourishing economic activities. Many educational, economic, and commercial agreements with the European Union were signed. Because most of these private universities are connected with European partner universities as one of the conditions for obtaining the license to work, they held developed educational management. In addition, they prove more advanced governance and organizational practices. On the other hand, state-owned universities are larger in their faculties and institutions, strictly ruled by laws and regulations.

After over ten years of war, destruction, and devastation on human, social, economic and environmental levels, sustainable development is critical considering the economic background and context that characterizes Syria, particularly with the declining capacity for higher education institutions in Syria. The urgent need for sustainable leadership and practices representing Syrian higher education is vital.

The challenges to improving strategic planning, incorporating sustainability in universities missions, enhancing Syrian higher education institutions' management structures, operations, human capital, and updating curricula and course offerings with sustainable development goals are needed. This describes universities in Syria as implementing conventional management approaches with a dominating bureaucratic structure (mainly at public universities) and a lack of dynamic, sustainable organizational cultures, which advocate for flexible and organic systems, 
establishing diversity and equity at different levels.

Situation Analysis on Sustainable Higher Education in Syria

To explore sustainable development and how its actions are integrated and practiced at Syrian universities, we performed diagnoses analysis in 2020 on a private university in Syria. An online questionnaire was designed to examine respondents' perception of the extent to which a sample of private Syrian universities is sustainable in its teaching, research, operations, and outreach. The online questionnaire is based on the sustainability assessment questionnaire. The sustainability assessment questionnaire is designed to examine the extent to which a university is sustainable in its teaching, research, operations, and outreach (SAQ 2020).

Analysis indicates research in the field of sustainable development is at a minimum extent of $37.5 \%$, to a bit of extent $25 \% .75 \%$ of the sample indicated they are not performing research related to sustainable development. Building construction, energy conservation, waste reduction practices, solid waste recycling, sustainable food programs, water conservation practices, sustainable transportation programs, and green purchasing practices are not integrated. $50.5 \%$ indicated a small extent, and $37 \%$ were not sure. The sample respondents have just started to map out sustainability within its strategy. Asked if the university under study uses sustainable development as a framework to report and communicate sustainability impact, $62.5 \%$ responded negatively. Asked if sustainable development goals are measured, $62.5 \%$ replied that there is no measurement, 37.5\% do not know. Asked if this university has set sustainability plans for $2030,75 \%$ responded that no plans are set. The institution under examination does not have centers or units for sustainability; $62.5 \%$ indicated negatively, $25 \%$ do not know. Examining extent criteria for hiring faculty members recognizes faculty members' contribution to sustainability $37.5 \%$ indicated minimum extent, $25 \%$ minor extent, and $25 \%$ are not sure. Examining the university's area provides staff development opportunities to enhance understanding, teaching, and research in sustainable development; $37.5 \%$ indicated minimum extent, $50 \%$ minor extent, and $12.5 \%$ unsure. Examining the extent this university provides training in sustainable leadership behaviors, $62.5 \%$ revealed the minimum extent and $25 \%$ minor extent. Studying extent students' groups across campus are directly involved in sustainable development initiatives, $62.5 \%$ indicated minimum extent, $12.5 \%$ slight extent, and $12.5 \%$ not sure. Examining the extent sustainability is reflected in the vision and mission of the university, $37.5 \%$ indicated minimum extent and $37.5 \%$ minor extent. University mission is traditional and has no explicit integration of concepts of sustainability. Examining if sustainable development is reflected in strategic planning, 25\% indicated minimum extent, $37.5 \%$ minor extent $\& 12.5 \%$ not sure.

The results indicate that sustainable leadership behavior training is provided at either minimum or minor extent. Sustainable strategy and university mission are 
practiced to a minimum extent. The analysis illustrates traditional mission statements do not incorporate sustainable development. The case demonstrates the need for actions in capacity building, raising awareness, and community engagement. The case illustrates the need to improve management and operation by shaping a sustainability culture.

\section{Discussion and Recommendation}

This research indicates that Syrian higher education is facing challenges related to integrating sustainable development initiatives at its operations, structures, and strategies. This research's recommendation focuses on improving management and operations by shaping a culture of sustainability incorporating sustainable development goals at Syrian higher education institutions. Through capacity building, raising awareness, and community engagement, Syrian higher education could be working on the implementation to enhance sustainable development in higher education in Syria.

Whereas urgent problems in preliminary need analysis are reflected in many aspects characterizing sustainable faculty and staff development, university structures, strategic planning and university mission, research and scholarship, services, operations, and students' opportunities.

Based on the results from the preliminary analysis, the recommends the introduction of a new concept of management and sustainable leadership behavior at Syrian higher education. This will address the lack of ability and capacity in sustainable leadership behaviors and practices among university management, executives, academics, and administrators.

Furthermore, the research recommends designing organic and sustainable organizational structures building sustainability steering committees and teams at Syrian higher education. This initiative will address sustainable integrating mechanisms such as creating sustainability task forces and steering committees and groups to coordinate and manage sustainability-related activities and initiatives, including research, teaching, knowledge transfers and training, campus management. Task forces and sustainability steering committees are members of mid-level management reporting to the top level. The developing unit of sustainability management will address problems mainly at group and institution levels.

Consequently, the research recommends that sustainable strategic planning is critical by introducing new visions and mission statements that integrate sustainability at Syrian universities. This initiative will address strategic problems at the institution level. However, all target group members can be engaged in developing a new sustainable vision for the Syrian universities.

\section{Conclusion}

This research illustrated the scope of sustainability in higher education in Syria with 
a focus on private universities. This research aims to improve management and operations by shaping a culture of sustainability incorporating sustainable development goals at Syrian higher education institutions.

The research explored dimensions associated with sustainability in higher education in Syria, highlighting its top significance for the sustainable future for Syrian Higher education.

Universities in Syria need the knowledge and expertise of social and technical innovation and skills to create a sustainable future for Syria. The new paradigm of sustainable management is characterized by a new vision for a green sustainable Syrian higher education institution after ten painful years of war and devastation.

The biggest challenge for Syrian universities in the near, intermediate, and longterm future is establishing operational mechanisms to introduce, develop, and enhance sustainability initiatives at university campus, services, curricula, learning and research, strategic planning, and university mission.

\section{References}

Almut Beringer, Tarah Wright, Leslie Malone. (2008). Sustainability in higher education in Atlantic Canada. International Journal of Sustainability in Higher Education, 9(1), http://dx.doi.org/10.1108/14676370810842184. 48 - 67.

Association of University Leaders for a Sustainable Future. (2021).

Dalati, S. (2021). Factors Affecting Syrian Female Researchers' Experience During Crisis: Inductive Approach. Business, Management and Economics Engineering, 19, 91-110.

Dalati, S., Raudeliuniene, J., \& Davidaviciene, V. (2020). Innovations in the management of higher education: Situation analysis of Syrian female students empowerment. Marketing and Management of Innovations, 4, 245-254.

Ira Haavisto, Gyöngyi Kovács. (2014). Perspectives on sustainability in humanitarian supply chains, Disaster Prevention and Management, 23(5), http://dx.doi.org/10.1108/DPM-10-2013-0192. 610 - 631.

Ko Nomura, Osamu Abe. (2010). Higher education for sustainable development in Japan: policy and progress. International Journal of Sustainability in Higher Education, 11(2), 120 - 129.

Luís Pedro, Amaral Nelson, Martins Joaquim, Borges Gouveia. (2015). Quest for a Sustainable University: a review. International Journal of Sustainability in Higher Education, 16(2). 
Matthias Barth, Jasmin Godemann, Marco Rieckmann, Ute Stoltenberg. (2007). Developing key competencies for sustainable development in higher education. International Journal of Sustainability in Higher Education, 8(4), 416 - 430.

Saju Jose, Jacob Chacko. (2016). Building a sustainable higher education sector in the UAE. International Journal of Educational Management,

Sustainable Development Goals. (2021). https://sustainabledevelopment.un.org/sdgs.

Tarah S. A. Wright. (2002). Definitions and frameworks for environmental sustainability in higher education. International Journal of Sustainability in Higher Education, 3(3), $203-220$.

ULSA Sustainability. (2021). What is Sustainability? https://www.sustain.ucla.edu.

UNESCO. (2021). UNESCO and Sustainable Development Goals. sdgs_poster_936_en.png <https://en.unesco.org/sustainabledevelopmentgoals.

United Nations. (2021). Reimagining the future for every child. https://www.un.org/en.

University of Ibadan. (2021). The Sustainability Assessment Questionnaire (SAQ). http://ulsf.org/sustainability-assessment-questionnaire. 